\title{
Papilloedema in Behcet's disease: value of MRI in diagnosis of dural sinus thrombosis
}

\author{
Kamal M El-Ramahi, M Zuheir Al-Kawi
}

\begin{abstract}
Behcet's disease is a multisystem disease characterised by the clinical triad of oral ulcers, genital ulcers and uveitis. Nervous system involvement is frequent and occasionally precedes other manifestations. Behcet's disease is not frequently considered in the differential diagnosis of papilloedema. We report four cases of Behcet's disease in which papilloedema occurred with or without dural sinus thrombosis. MRI is of great value in the investigation of such patients as it can demonstrate venous sinus thrombosis non-invasively or suggest the diagnosis by showing the associated parenchymal lesions secondary to small vessel pathology.
\end{abstract}

Behcet's disease is recognised as a multisystem disease. Besides the classic triad of recurrent oral ulcers, genital ulcers and uveitis a wide spectrum of signs have been reported. ${ }^{1}$ Any part of the neuraxis can be involved with a predilection to the brainstem and diencephalon. ${ }^{2}$ Vascular manifestations include arterial occlusions, thrombosis, aneurysmal formation $^{3}$ and venous thrombosis, ${ }^{4}$ papilloedema without associated uveitis may occur as a presenting manifestation. It is usually attributed to dural sinus thrombosis, ${ }^{5}$ but well documented cases of such occurrences are rare even in countries where the disease is frequent. Our report emphasises this finding and demonstrates the value of MRI in the diagnosis of dural sinus thrombosis.

\section{Case Report 1}

A 22 year old Saudi female presented with decreased vision, headaches, nausea, vomiting and abdominal pain. History of recurrent oral and genital ulcers, skin papules and pustules, and arthritis was obtained.

Funduscopy revealed bilateral papilleodema and retinal vasculitis. Visual acuity was down to light perception in the left eye and counting fingers at 3 metres in the right.

Neurological examination showed left arm drift and left sixth nerve paresis. Other positive findings were oral ulcers, papulo-pustular skin lesions and right knee swelling and tenderness.

Prothrombin time (PT), partial thromboplastin time (PTT), fibrinogen, reptilase time and antithrombin III were normal. Erythrocyte sedimentation rate (ESR) was $45 \mathrm{~mm} /$ h, platelets $545 \times 10^{3} / \mathrm{ml}^{3}$. Euglobulin lysis time was abnormally prolonged; pre stress $8 \mathrm{~h}$ (N 2-6 h) and post stress $7 \mathrm{~h}(\mathrm{~N} \mathrm{40-80} \mathrm{min-}$ utes).

CT scan of the brain with contrast showed a filling defect in the superior sagittal sinus
(Delta sign) (fig 1). MRI of the head showed superior sagittal and straight sinus thromboses (fig 2). Cerebral angiography by intraarterial injection confirmed superior sagittal sinus thrombosis (fig 3). Lumbar puncture opening pressure was $360 \mathrm{~mm} \mathrm{H}_{2} \mathrm{O}$ with normal cells, glucose and protein.

She was treated with heparin and prednisone $60 \mathrm{mg}$ a day and her visual acuity improved slightly. The vitreous cellular infiltrate and retinal vasculitis disappeared.

Repeat MRI of the brain showed evidence of recanalisation of the thrombosed sagittal sinus (fig 4). Addition of Azathioprine did not result in any further improvement. She was then maintained on prednisone $10 \mathrm{mg}$ daily. There was no recurrence of oral or genital ulcers, skin lesions or arthritis on this regime. Visual acuity remained unchanged 14 months later.

Case Report 2

A 19 year old Saudi female presented in 1983 with headache, rapidly deteriorating vision, vomiting and arthritis of her knees. She had recurrent oral and genital ulcers. Bilateral papilloedema without uveitis was present. Visual acuity was $6 / 60$. She was given prednisone $60 \mathrm{mg}$ daily. Headache and oral ulcers recurred whenever the dose of prednisone was decreased. Examination revealed left sixth nerve palsy and multiple skin boils on the buttocks.

Laboratory data revealed ESR $108 \mathrm{~mm} / \mathrm{h}$, rheumatoid factor (RF), antinuclear antibody (ANA), C-reactive protein (CRP), rapid plasmin reagin (RPR), circulating immune complexes (CIC) and antithrombin III were nor-

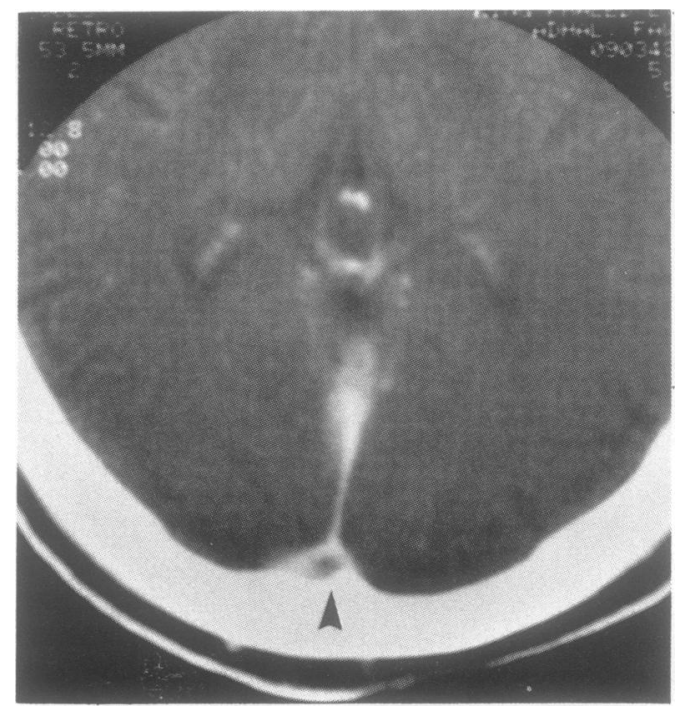

Figure 1 Enhanced CT scan of the head. Patient 1 showing a filling defect in the superior sagittal sinus (Delta sign) (arrowhead). 
Figure 2 Gadolinium enhanced MRI of the head $T 1$ weighted image (TR 2000 TE20). (Patient 1) Showing irregular filling defects in the straight sinus (arrowheads) and the superior sagittal sinus.
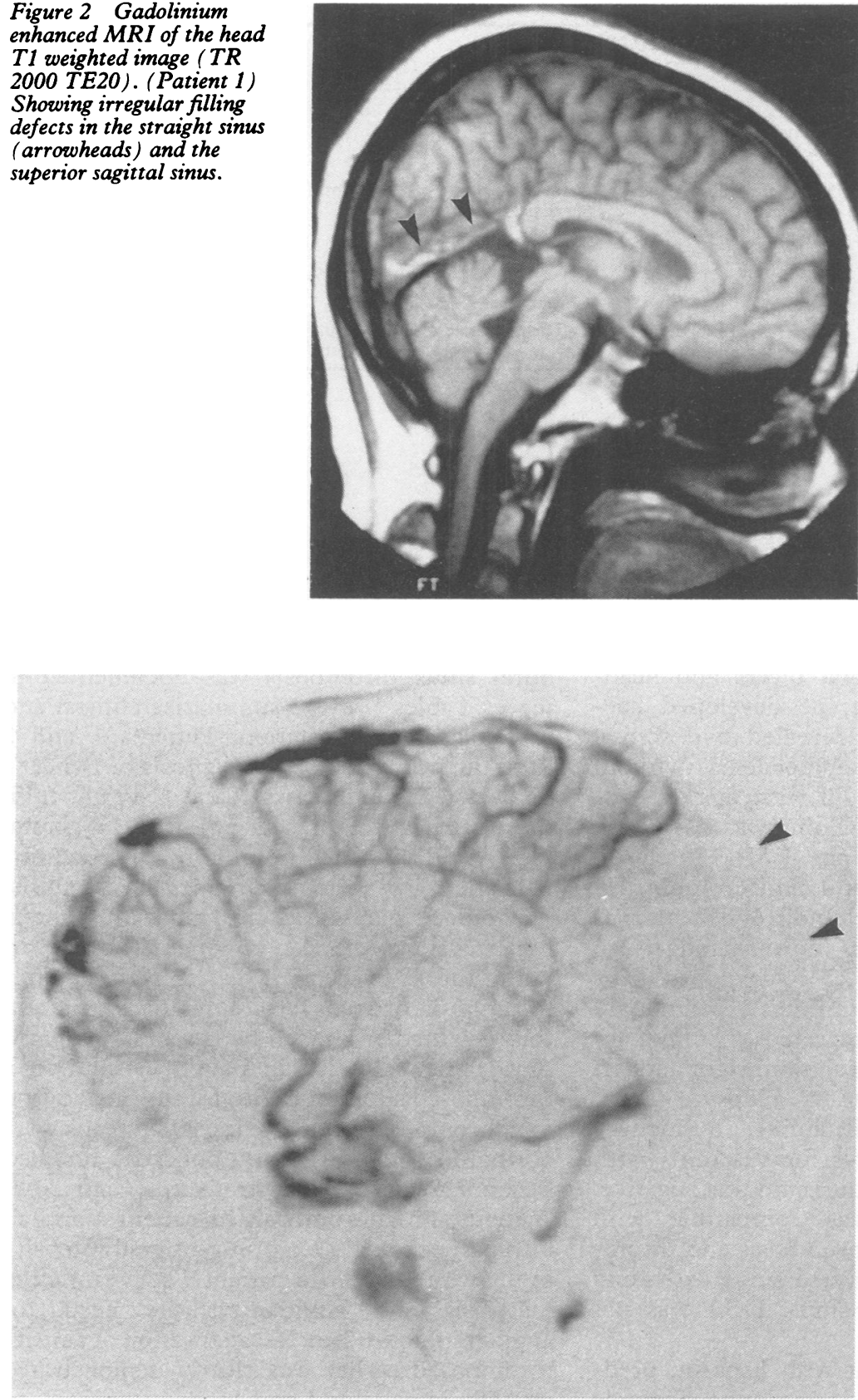

Figure 3 Cerebral angiography confirms non-filling of the posterior half of the superior sagittal sinus (arrowhead) and the straight sinus. (Patient 1).

Figure 4 Gadolinium enhanced MRI of the head $T 1$ weighted image (TR2000 TE20).

(Patient 1) showing filling of the recanalised superior sagittal sinus. mal. Euglobulin lysis time was considerably prolonged with no lysis in 24 hours.

CT scan of the brain suggested transverse sinus occlusion with marked venous collaterals and venous dilatation.

Carotid angiogram showed complete occlusion of the right transverse sinus and at the mid left transverse sinus. Lumbar puncture opening pressure was $320 \mathrm{~mm} \mathrm{H}_{2} \mathrm{O}$. CSF analysis was normal. Lumbo-peritoneal shunt was performed followed by treatment with prednisone and chlorambucil. Vision remained impaired. Repeat digital substraction angiography (DSA) by intra-arterial injection showed occlusions of both transverse sinuses. Five years later she developed episcleritis of the right eye which recurred a year later.

Case Report 3

A 23 year old Saudi male presented to another hospital in September 1988 with headaches, blurred vision and horizontal diplopia. After normal CT scan he was diagnosed as having benign intracranial hypertension. Symptoms subsided spontaneously within one month. In November 1988, he experienced sudden weakness of his left arm which subsided spontaneously after two weeks. In May 1989 he developed intermittent fever with chills, shortness of breath, right sided pleuritic pain and palpitation. He was re-admitted to the local hospital with fever and bilateral papilloedema. Echocardiogram showed a right ventricular mass, he was then referred to our hospital.

History of recurrent oral and genital ulcers was confirmed. Multiple fresh ulcers on the lips, tongue and cheeks and two scrotal scars were present. There was no uveitis, papilloedema nor were there any neurological deficit detected on examination in our hospital. Pulse in the Right Radial artery was absent.

Pertinent laboratory data included, leucocytosis $22.6 \times 10^{3} / \mathrm{ml}^{3}$, platelets $328 \times$ $10^{3} / \mathrm{ml}^{3}$ and raised ESR $116 \mathrm{~mm} / \mathrm{h}$. The following laboratory tests gave negative or normal results, RF, ANA, CRP, PT, PTT, plasminogen, reptilase time and antithrombin III. Euglobulin lysis time was prolonged to eight hour pre-stress (N 2-6 h) and seven hour post-stress (N 40-80 minutes). Bilateral pulmonary emboli were detected on scintigraphy, and a right ventricular thrombus on echocardigram and right ventriculogram. Pulmonary angiography revealed pulmonary vasculitis.

CT scan of the head at the referring hospital was negative. MRI of the head showed a $0.5 \mathrm{~cm}$ area of high signal intensity in the deep white matter in the right parietal region on T2 weighted images. No dural sinus thrombosis was present, digital substraction angiography was not performed.

He was treated with prednisone $60 \mathrm{mg} /$ day, azathioprine and warfarin. At a twelve month follow up, no recurrence of papilloedema nor any visual or neurological manifestations were present. He continued to receive prednisone $10 \mathrm{mg} /$ day, azathioprine and warfarin. 
Table 1 Summary of clinical features and selected laboratory results

\begin{tabular}{|c|c|c|c|c|c|c|c|c|c|c|}
\hline No & $\begin{array}{l}\text { Sex/ } \\
\text { age }\end{array}$ & $\begin{array}{l}\text { Oral } \\
\text { ulcers }\end{array}$ & $\begin{array}{l}\text { Genital } \\
\text { ulcers }\end{array}$ & $\begin{array}{l}\text { Skin } \\
\text { lesions }\end{array}$ & Arthritis & $\begin{array}{l}\text { Occular } \\
\text { manifestations }\end{array}$ & $\begin{array}{l}\text { Neurological } \\
\text { manifestations }\end{array}$ & $E S R$ & $\begin{array}{l}\text { Euglobulin } \\
\text { lysis time }\end{array}$ & $\begin{array}{l}\text { Dural sinus } \\
\text { thrombosis }\end{array}$ \\
\hline 1 & $F / 22$ & + & + & + & + & $\begin{array}{l}\text { Bilateral papilloedema } \\
\text { Retinal vasculitis } \\
\text { Visual acuity } \\
\text { Light perception }\end{array}$ & $\begin{array}{l}\text { Left sixth } \\
\text { nerve palsy }\end{array}$ & $45 \mathrm{~mm} / \mathrm{h}$ & Prolonged & + \\
\hline 2 & $\mathrm{~F} / 19$ & + & + & + & + & $\begin{array}{l}\text { Bilateral papilloedema } \\
\text { Episcleritis } \\
\text { Visual acuity } \\
\text { Right-light } \\
\text { perception } \\
\text { Left-No light } \\
\text { perception }\end{array}$ & $\begin{array}{l}\text { Left sixth } \\
\text { nerve palsy }\end{array}$ & $108 \mathrm{~mm} / \mathrm{h}$ & Prolonged & + \\
\hline $\begin{array}{l}3 \\
4\end{array}$ & $\begin{array}{l}M / 23 \\
M / 18\end{array}$ & $\begin{array}{l}+ \\
+\end{array}$ & $\begin{array}{l}+ \\
+\end{array}$ & - & - & Bilateral papilloedema & Left arm weakness & $116 \mathrm{~mm} / \mathrm{h}$ & Prolonged & $\bar{t}$ \\
\hline
\end{tabular}

Case Report 4

An 18 year old Saudi male presented with fever of three months duration and history of recurrent oral and scrotal ulcers and headaches. Upon admission, he developed haemoptysis. Examination revealed two scrotal ulcers and bilateral papilloedema without uveitis. He was acutely ill with marked respiratory distress. Haemoglobin was $7 \cdot 7 \mathrm{gm} / \mathrm{dl}$, platelets $821 \times 10^{3} / \mathrm{ml}^{3}$ and ESR $150 \mathrm{~mm} / \mathrm{h}$. Lupus anti-coagulant and antithrombin III were negative while euglobulin lysis time was prolonged to 21 hours (normal range 2-6 hours) pre-stress and 22 hours post-stress (normal range 40-80 minutes). Pulmonary scintigraphy strongly suggested of pulmonary emboli. Echocardiogram showed right and left ventricular masses, and a biopsy of one proved it to be a thrombus. Pulmonary angiography was positive for vasculitis with aneurysms. CT scan of the brain was negative. MRI of the head was compatible with superior sagittal sinus thrombosis and thrombosis of the right transverse sinus extending into the right sigmoid sinus. DSA was not carried out.

After initial treatment with heparin, prednisone $60 \mathrm{mg} /$ day and cyclophosphamide $100 \mathrm{mg} /$ day were added, he became asymptomatic.

A repeat MRI of the head before discharge showed recanalisation of the thrombosed sinuses. Papilloedema resolved and he remained well during the next twenty months of follow up. Cyclophosphamide was discontinued and prednisone maintained at $5 \mathrm{mg} /$ day.

\section{Discussion}

Four cases with Behcet's disease are presented, papilloedema was present in all, evidence of dural sinus thrombosis was documented in three. Tables 1 and 2 summarise clinical and radiological manifestation. Patients 1 and 2 fulfil the new criteria for diagnosis of Behcet's disease. ${ }^{6}$ Although cases 3 and 4 do not fulfil these criteria, the presence of oral and genital ulcers and evidence of pulmonary vasculitis with aneurysm strongly supports the diagnosis.

Papilloedema, headache and intracranial hypertension were seen in patients 1 and 2 . In both, the CT scans revealed sagittal sinus thrombosis or transverse sinus occlusion and this was further elicited by cerebral angiography (table 2). MRI in patient 1 showed a thrombosed superior sagittal sinus, in addition to a thrombosed straight sinus. CT scans were normal in patients 3 and 4 but MRI revealed superior sagittal, right transverse and right sigmoid sinus thrombosis in patient 4 and an intraparenchymal area of high signal intensity in the white matter in patient 3 suggesting the diagnosis and eliminating the need for angiographic studies. Recanalisation of sinuses thrombosed earlier was clearly demonstrated on MRI in patients 1 and 4.

Papilloedema, headache and vomiting as manifestations of raised intracranial pressure in Behcet's disease were first reported by Masheter in $1959 .^{7}$ Papilloedema without headache and vomiting was also described by Wadia in $1957^{8}$ and Berlin in $1960 .^{9}$ Five cases of papilloedema in Behcet's disease were reported by Kalbian in 1970. It was not accompanied

Table 2 Summary of the imaging features and CSF pressure

\begin{tabular}{|c|c|c|c|c|c|}
\hline No & Headache & $\begin{array}{l}\text { CSF opening } \\
\text { pressure }\end{array}$ & CT scan & MRI & Cerebral angiography \\
\hline 1 & + & $360 \mathrm{~mm} \mathrm{H}_{2} \mathrm{O}$ & $\begin{array}{l}\text { Superior Sagittal } \\
\text { sinus thrombosis }\end{array}$ & $\begin{array}{l}\text { Superior Sagittal and straight } \\
\text { sinus thrombosis }\end{array}$ & $\begin{array}{l}\text { Superior Sagittal sinus } \\
\text { thrombosis }\end{array}$ \\
\hline 2 & + & $320 \mathrm{~mm} \mathrm{H}_{2} \mathrm{O}$ & $\begin{array}{l}\text { Transverse sinus } \\
\text { occlusion }\end{array}$ & ND & $\begin{array}{l}\text { Right transverse and mid-left } \\
\text { sinus occlusion }\end{array}$ \\
\hline 3 & + & ND & Normal & $\begin{array}{l}0.5 \mathrm{~cm} \text { high intensity signal in } \\
\text { the deep white matter in } \\
\text { the parietal region }\end{array}$ & ND \\
\hline 4 & + & ND & Normal & $\begin{array}{l}\text { Superior Sagittal, Right transverse } \\
\text { and Right sigmoid sinus thrombosis }\end{array}$ & ND \\
\hline
\end{tabular}

$+=$ Present.

ND $=$ Not done. 
or preceded by uveitis in two patients. ${ }^{5}$

Various imaging methods were utilised in the diagnosis of dural sinus thrombosis. The gold standard has been cerebral angiography showing a filling defect in the superior sagittal sinus and prolonged cerebral circulation. ${ }^{10-21}$ DSA provided the advantage of improved images and decreased amount of contrast needed.

MRI was reported to show abnormal signal in thrombosed dural sinuses of various aetiologies. Also MRI was used to demonstrate brain abnormalities in Behcet's disease, ${ }^{21-24}$ but there are no reports documenting dural sinus thrombosis by MRI in Behcet's disease.

CT scan is useful in showing changes compatible with dural thrombosis. ${ }^{12}$ But it is less sensitive than angiography and a negative CT does not rule out dural sinus thrombosis. ${ }^{1016}$

Decreased fibrinolytic activity was reported in some patients with pseudotumour cerebri and suggested an unfavourable prognosis associated with recurrence or severe complications. ${ }^{25}$ Diminished fibrinolytic activity in the peripheral blood of patients with Behcet's disease has also been reported. ${ }^{26}$ This may partly explain the predilection of patients with Behcet's disease to develop thrombotic events in general, and dural sinus thrombosis in particular with subsequent raised intracranial pressure. Our data are consistent with this observation. Another potential cause for pseudotumour cerebri in these patients includes sudden withdrawal of corticosteroids, this was not the case in any of our patients.

We recommend MRI in patients with Behcet's disease presenting with papilloedema and support the theory that these may be due to dural sinus thrombosis. 1 Shimizu T, Ehrlich GE, Inaba G, Hayashi K. Behcet disease 2 O'Duffy JD, Goldstein NP. Neurological involvement in 7 patients with Behcet's disease. Am J Med 1976;61:170-8. Hamza $M$. Large artery involvement in Behcet's disease. Rheumatol 1987;14:554-9.

4 Chajek T, Fainaru M. Behcet's disease. Report of 41 cases and review of the literature. Medicine 1975;54:179-96.

5 Kalbian VV, Challis MT. Behcet's disease. Report of Twelve cases with three manifesting as papilledema. Am J Med 1970;49:823-9.

6 International Study Group for Behcet's Disease. Criteria for diagnosis of Behcet's Disease. Lancet 1990;335:1078-80.

7 Masheter HC. Behcet's syndrome complicated by intracranial thrombophlebitis. Proc Roy Soc Med 1959;52:1039-40. 8 Wadia N, Williams E. Behcet's syndrome with neurological complications. Brain 1957;80:59-63.

9 Berlin C. Behcet's disease as a multiple system complex. Arch Derm 1960;82:73-79.

10 Pamir MN, Kansu T, Erbengi A, Zeileli T. Papilledema in Behcet's syndrome. Arch Neurol 1981;88:643-5.

11 Bousser MG. Cerebral vein thrombosis in Behcet's syndrome (letter). Arch Neurol 1982;39:322.

12 Rosenberger A, Adler OB, Haim S. Radiological aspects of Behcet's disease. Radiology 1982;144:261-4.

13 Bank I, Weart C. Dural sinus thrombosis in Behcet's disease. Arthritis Rheum 1984;27:816-18.

14 Bousser MG, Chiras J, Bories J, Castaigne P. Cerebral venous thrombosis. A review of 38 cases. Stroke 1985; 16:199-213.

15 Wechsler B, Bousser MG, Houng DU LT et al. Cerebral venous sinus thrombosis in Behcet's disease (letter). Mayo Clin Proc 1985;60:891.

16 Brissaud P, Laroche L. De Gramont A, Krulik M. Digital angiography for the diagnosis of dural sinus thrombosis in Behcet's disease. Arthritis Rheumatism 1985;28:359-60.

17 Harper CM, O'Neill BP, O'Duffy JD, Forbes GS. Intracranial hypertension in Behcet's disease: Demonstration of sinus occlusion with use of Digital Substraction Angiography. Mayo Clin Proc 1985;60:419-22.

18 Ben-Itzhak J, Keren S, Simon J. Intracranial thrombosis in Behcet's syndrome. Neuro Radiology 1985;27:450.

19 Barbas CSV, de Carvalho CPP, Delmonte VC, et al. Behcet's disease. A rare case of simultaneous pulmonary and cerebral involvement. Am J Med 1988;85:576-8.

20 Serdaroglu P, Yazici H, Ozdemir C, et al. Neurologic involvement in Behcet's syndrome. A prospective study. Arch Neurol 1989;46:265-9.

21 Willeit J, Schmutzhard E, Aichner F, et al. CT and MR imaging in Neuro Behcet's disease. J Comput Assist Tomogr 1986;10:313-18.

22 Fukuyama $\mathrm{H}$, Kameyama $\mathrm{M}$, Nabatame $\mathrm{H}$, et al. Magnetic resonance images of neuro-Behcet syndrome show precise brain stem lesions. Report of a Case. Acta Neurol Scand 1987;75:70-73.

23 Vidaller A, Carratala J, Moreno R, et al. Magnetic Resonance Imaging in Neuro-Behcet's Disease (letter). $\mathrm{Br} J$ Rheumatology 1988:27(1):79-80.

24 Purvin V, Dunn DW, Edwards M. MRI and cerebral venous thrombosis. Comp Radiol 1987;11:75-79.

25 Al-Kawi MZ, Chavis P, Bashir R, et al. Fibrinolysis in pseudo tumor cerebri in brain edema, pathogenesis, in pseudo tumor cerebri in brain edema, pathogenesis, imaging and therapy, $\mathrm{D}$
ology, Vol 52 . 1990:539.

26 Mishima H, Masuda K, Shjimada S, et al. Plasminogen activators activity levels in patients with Behcet's Syndrome. Arch Ophthalmology 1985;103:935-6. 